\title{
A laparoscopic approach may be used to improve the surgical management of advanced ovarian cancer
}

\author{
Michel Canis • Kris Jardon • \\ Benoît Rabischong • Gérard Mage
}

Received: 18 December 2007 / Accepted: 21 December 2007 / Published online: 16 January 2008

(C) Springer-Verlag 2008

\begin{abstract}
A laparoscopic approach may be used to improve the surgical management of advanced ovarian cancer.
\end{abstract}

Keywords Ovarian cancer· Laparoscopy · Surgery · Laparotomy

Recent papers [1-5] reemphasized that the survival outcome of advanced ovarian cancer is related to the quality of the initial operation and that optimal debulking is more often achieved by gynecologic oncologists than by other specialty surgeons, meaning that the initial surgical care of ovarian cancer should be concentrated in a gynecologic oncology center. However, at the present time, only $50 \%$ of ovarian cancers are initially managed by a qualified gynecologic oncologist [2]. To improve this situation, there are two possibilities: to refer the patient before surgical diagnosis or before treatment when the diagnosis of ovarian cancer has been confirmed by permanent sections. Obviously, the ideal situation would be to refer all patients to oncology departments before the surgical diagnosis. However, currently, this ideal situation appears to be unrealistic.

In contrast, using all of the advantages of endoscopic surgery, it does seem possible today to improve the management of patients with ovarian cancer by referring all patients with advanced ovarian cancer to a compre-

M. Canis $(\varangle) \cdot \mathrm{K}$. Jardon $\cdot$ B. Rabischong $\cdot$ G. Mage

Department of Obstetrics Gynecology and Reproductive Medicine, CHU_Centre Hospitalier Universitaire de Clermont Ferrand,

Polyclinique de l'Hôtel Dieu,

Boulevard Léon Malfreyt,

63058 Clermont-Ferrand, France

e-mail: mcanis@chu-clermontferrand.fr hensive cancer center before treatment. Ovarian cancers are diagnosed in two surgical circumstances: surgical diagnosis of a peritoneal carcinomatosis and the management of a suspicious adnexal mass without any peritoneal dissemination.

In patients with advanced disease, laparoscopy was recently proposed for assessing whether the disease may be optimally debulked by laparotomy $[6,7]$. Furthermore, it was shown that, in this indication, trocar site metastasis does not worsen the prognosis for patients with advanced ovarian cancer managed using primary or interval debulking after three cycles of chemotherapy [8]. The value of interval debulking after three cycles of neoadjuvant chemotherapy is questionable. A meta-analysis comparing neoadjuvant chemotherapy and interval debulking with the usual initial surgical debulking showed that neoadjuvant chemotherapy is associated with a lower rate of survival [9]. Each preoperative cycle of chemotherapy was associated with a mean decrease in survival the time of 4.1 months [9]. However, each $10 \%$ increase in the incidence of optimal debulking was associated with a 1.9-month increase in the median survival time [9], confirming a previous meta-analysis which showed an increase in the survival time of 1.5 months with each $10 \%$ increase in the incidence of optimal debulking [10].

From these data, we propose that laparoscopy should be used as a diagnostic procedure to assess all patients with peritoneal carcinomatosis of unknown origin who are not referred to a gynecologic oncology department before the surgical diagnosis. In the case of macroscopically confirmed ovarian cancer, the procedure would be stopped after taking samples for cytology, biopsies of peritoneal metastasis for permanent sections, and pictures of the specific peritoneal areas used by oncologists to decide whether or not peritoneal carcinomatosis is resectable. 
Then, the patient would be referred immediately to a comprehensive cancer center with the pathologic results and a compact disk of the laparoscopy accompanied by a detailed operative report would be produced.

Thanks to the decreased trauma associated with laparoscopic surgery, a second operation or medical treatment is possible less than a week later. This would be impossible if the initial surgical diagnosis was achieved by laparotomy. In the oncology department, decisions concerning the management would be taken according to the extent of the disease and the possibilities for scheduling surgery within a few days. As most oncology centers are normally busy, it may be difficult to organize early debulking operations for all of these patients, but it is almost always possible to start chemotherapy as soon as the diagnosis has been confirmed with permanent sections. If patients were referred only after the diagnosis, giving one cycle of chemotherapy would decrease the survival by 4.1 months [9]. However, by changing the surgeon, the rate of optimal debulking would probably increase from $40 \%$ to $70 \%$ [2], so the median survival time could increase by 4.5 to 5.7 months $[9,10]$. This simple change in the usual management of patients with peritoneal carcinomatosis of unknown etiology would allow consistent centralized referral for the surgical treatment of all patients with ovarian cancer, without worsening the prognosis of these patients $[3,8]$.

Obviously, as not all of the patients operated for a suspicious adnexal mass have a stage III or IV ovarian cancer, surgeons managing them should know all of the rules for an adequate laparoscopic diagnostic procedure and how to treat benign masses while preserving the ovary whenever possible [11]. They should also know that, when an adnexal mass is diagnosed as suspicious at surgery, but is accompanied by no peritoneal dissemination, surgical puncture should be avoided and the mass should be entirely and immediately removed [11]. Indeed, national surveys on the inadequate laparoscopic management of undiagnosed ovarian cancer showed that tumor dissemination is very likely to occur if the adnexa is removed only several days or weeks after biopsy or puncture of the mass $[12,13]$. In some cases, of course, removal of the adnexa will require immediate laparotomy [11, 14], as ovarian masses are absolute contraindications to morcellation [15]. After the adnexectomy, these patients with an early ovarian cancer would be referred to an oncology department for a restaging procedure. Since, in young patients, the results of permanent sections are often necessary to decide whether or not the conservative treatment of an ovarian cancer is possible, an interval between the adnexectomy and the staging operation is often inevitable to propose the optimal management.
During this initial laparoscopic procedure, the surgical rules designed to prevent trocar site metastasis should be applied [16-18]. As trocar site excision should be performed at the time of debulking procedures, the first and second trocar sites should be placed along the future midline incision and the lateral trocars should be inserted perpendicularly to the abdominal wall so that the scar may be reliably excised [11].

So, making the most of the advantages offered by laparoscopy, it is possible to offer optimal surgical treatment to every patient without worsening the prognosis.

\section{References}

1. Aletti GD, Gostout BS, Podratz KC, Cliby WA (2006) Ovarian cancer surgical resectability: relative impact of disease, patient status, and surgeon. Gynecol Oncol 100:33-37

2. Bristow RE (2006) Predicting "unresectable" ovarian cancer: taking aim at a moving target. Gynecol Oncol 100:449-450

3. Bristow RE, Berek JS (2006) Surgery for ovarian cancer: how to improve survival. Lancet 367:1558-1560

4. Bristow RE, Zahurak ML, del Carmen MG, Gordon TA, Fox HE, Trimble EL, Montz FJ (2004) Ovarian cancer surgery in Maryland: volume-based access to care. Gynecol Oncol 93: 353-360

5. Goff BA, Matthews BJ, Wynn M, Muntz HG, Lishner DM, Baldwin LM (2006) Ovarian cancer: patterns of surgical care across the United States. Gynecol Oncol 103:383-390

6. Angioli R, Palaia I, Zullo MA, Muzii L, Manci N, Calcagno M, Panici PB (2006) Diagnostic open laparoscopy in the management of advanced ovarian cancer. Gynecol Oncol 100:455-461

7. Deffieux X, Castaigne D, Pomel C (2006) Role of laparoscopy to evaluate candidates for complete cytoreduction in advanced stages of epithelial ovarian cancer. Int J Gynecol Cancer 16 (Suppl 1):35-40

8. Vergote I, Marquette S, Amant F, Berteloot P, Neven P (2005) Port-site metastases after open laparoscopy: a study in 173 patients with advanced ovarian carcinoma. Int $\mathrm{J}$ Gynecol Cancer 15(5):776-779

9. Bristow RE, Chi DS (2006) Platinum-based neoadjuvant chemotherapy and interval surgical cytoreduction for advanced ovarian cancer: a meta-analysis. Gynecol Oncol 103:1070-1076

10. Bristow RE, Tomacruz RS, Armstrong DK, Trimble EL, Montz FJ (2002) Survival effect of maximal cytoreductive surgery for advanced ovarian carcinoma during the platinum era: a metaanalysis. J Clin Oncol 20:1248-1259

11. Canis M, Botchorishvili R, Manhes H, Wattiez A, Mage G, Pouly JL, Bruhat MA (2000) Management of adnexal masses: role and risk of laparoscopy. Semin Surg Oncol 19:28-35

12. Maiman M, Seltzer V, Boyce J (1991) Laparoscopic excision of ovarian neoplasms subsequently found to be malignant. Obstet Gynecol 77:563-565

13. Lehner R, Wenzl R, Heinzl H, Husslein P, Sevelda P (1998) Influence of delayed staging laparotomy after laparoscopic removal of ovarian masses later found malignant. Obstet Gynecol 92:967-971

14. Vergote I, De Brabanter J, Fyles A, Bertelsen K, Einhorn N, Sevelda P, Gore ME, Kaern J, Verrelst H, Sjövall K, Timmerman D, Vandewalle J, Van Gramberen M, Tropé CG (2001) Prognostic importance of degree of differentiation and cyst rupture 
in stage I invasive epithelial ovarian carcinoma. Lancet 357: 176-182

15. Canis M, Pouly JL, Wattiez A, Mage G, Manhes H, Bruhat MA (1997) Laparoscopic management of adnexal masses suspicious at ultrasound. Obstet Gynecol 89:679-683

16. Ramirez PT, Wolf JK, Levenback C (2003) Laparoscopic port-site metastases: etiology and prevention. Gynecol Oncol 91:179-189
17. Steinert R, Lippert H, Reymond MA (2002) Tumor cell dissemination during laparoscopy: prevention and therapeutic opportunities. Dig Surg 19:464-472

18. van Dam PA, DeCloedt J, Tjalma WA, Buytaert P, Becquart D, Vergote IB (1999) Trocar implantation metastasis after laparoscopy in patients with advanced ovarian cancer: can the risk be reduced? Am J Obstet Gynecol 181:536-541 